\title{
Prognostic criteria in patients with gastrointestinal stromal tumors: a single center experience retrospective analysis
}

\author{
Naoki Tanimine, Kazuaki Tanabe*, Takahisa Suzuki, Noriaki Tokumoto and Hideki Ohdan
}

\begin{abstract}
Background: Gastrointestinal stromal tumors (GISTs) are morphologically and clinically heterogeneous tumors, and their biological behavior is difficult to predict, ranging from clinically benign to malignant. The aim of our study was to reanalyze the value of the commonly used prognostic criteria and recently reported nomogram in predicting disease recurrence in patients with primary resectable GISTs.

Methods: The clinicopathological features of 60 patients with GISTs who underwent surgical resection between 1998 and 2010 at Hiroshima University Hospital were retrospectively reviewed. Tumors were classified according to the National Institutes of Health and Armed Forces Institute of Pathology criteria, and nomogram predictions were performed. The relationship between patient and tumor characteristics was tested by univariate analysis using the log-rank test. Furthermore, we assessed nomogram performance with the concordance index and calibration.

Results: The median patient follow-up was 4.1 years, with 6 of 60 patients experiencing recurrence. Recurrence was observed only in the high-risk group. The recurrence-free survival (RFS) was 93.0 and $89.9 \%$ after 2 and 5 years, respectively. The concordance indices of the nomogram prediction were 0.96 and 0.65 for all patients and the high-risk subgroup, respectively. Calibration of the nomogram-predicted RFS tended to overestimate the recurrence risk relative to the actual RFS.

Conclusions: Although the commonly used criteria provide an excellent estimation of tumor behavior, they are limited by prognostic heterogeneity. The predictive nomogram is a beneficial scoring system but not a direct RFS predictor. We need more consideration for small GISTs, particularly those less than $3 \mathrm{~cm}$ in diameter, and small GISTs should be analyzed as a subset with potentiality different biological behavior.
\end{abstract}

Keywords: gastrointestinal stromal tumor (GIST), prognostic criteria, recurrence, nomogram, adjuvant therapy

\section{Background}

Gastrointestinal stromal tumor (GIST) is the most common mesenchymal neoplasm of the intestinal tract. The tumor typically occurs in the stomach or small intestine, infrequently in the colon, rectum, and esophagus, and rarely outside the gastrointestinal tract. The gold standard therapy for localized primary GIST is surgical resection $[1,2]$. Unfortunately, the results of surgery alone have been inadequate, with up to $50 \%$ of patients

\footnotetext{
* Correspondence: ktanabe2@hiroshima-u.ac.jp
Department of Surgery, Division of Frontier Medical Science, Graduate

* Correspondence: ktanabe2@hiroshima-u.ac.jp

School of Biomedical Sciences, Hiroshima University, 1-2-3 Kasumi Minami-ku Hiroshima 734-8551, Japan
}

(c) 2012 Tanimine et al; licensee BioMed Central Ltd. This is an Open Access article distributed under the terms of the Creative Commons Attribution License (http://creativecommons.org/licenses/by/2.0), which permits unrestricted use, distribution, and reproduction in any medium, provided the original work is properly cited. tually dying from the disease [3-5].

In 2000, imatinib mesylate (Novartis Pharmaceuticals, Basel, Switzerland) was found to be effective against metastatic GIST in the initial patient tested [6], and its efficacy was then confirmed in a phase II $[7,8]$ and in phase III trials [9,10]. In 2009, the American College of Surgeons Oncology Group (ACOSOG) reported the results of study Z9001, a randomized control trial assessing the efficacy of adjuvant imatinib for patients with primary GISTs larger than $3 \mathrm{~cm}$ [11]. More recently, at the American Society of Clinical Oncology (ASCO) 47th Annual Meeting, the results of the SSG XVIII-AIO study were presented. This phase III trial revealed that 3 
years of treatment with imatinib after surgery in patients with high-risk GIST according to the National Institutes of Health (NIH) criteria [12], including patients who had tumor rupture before or during surgery, improved overall and recurrence-free survival (RFS) compared to the finding after 1 year of treatment.

GISTs are morphologically and clinically heterogeneous tumors, and their biological behavior is difficult to predict, ranging from clinically benign to malignant. The NIH criteria are based on the evaluation of the size and mitotic rate of the tumors as the most reliable prognostic factors, and their use is common. Another set of commonly used criteria that considers a third prognostic factor-tumor location-was proposed by the Armed Forces Institute of Pathology (AFIP) [13,14]. In addition, Gold et al. reported that their prognostic nomogram provided a better prediction of the likelihood of recurrence for individual patients in Western datasets than the commonly used staging criteria that stratify patients into a few broad groups [15].

The aim of our study was to reanalyze the value of the prognostic criteria regarding their relationship to disease recurrence in patients with primary resectable GISTs in our prospectively collected tumor registry as a Japanese dataset.

\section{Methods}

From 1998 to 2010, 60 patients presented to our institution with primary GIST without metastasis. Patient, tumor, and treatment data were collected prospectively. Complete gross resection of the tumor was performed in all patients. The technique of resection was at the discretion of the individual surgeon. An expert pathologist confirmed the diagnosis of GIST and calculated the mitotic index. The diagnosis of GIST was confirmed by immunohistochemical staining for CD117. The mitotic index was determined by counting the number of mitotic figures per 50 high-power fields (HPFs) and categorized as less than 5 or 5 or more mitoses. Size measurements were performed by the institutional pathologists, either before or after formalin fixation, and tumors were categorized as $5 \mathrm{~cm}$ or less or more than 5 $\mathrm{cm}$ in diameter. Tumors were classified according to the $\mathrm{NIH}$ and AFIP criteria, which are 2 commonly used sets of criteria (Table 1). Simultaneously, nomogram predictions were performed for the tumors [15]. The nomogram assigned points based on tumor size in a continuous but non-linear fashion. Points for tumor site were assigned on the basis of whether the tumor arose in the stomach, small intestine, colon/rectum, or an extraintestinal location, and points for mitotic index were assigned on the basis of whether the primary tumor had less than 5 or 5 or more mitoses per HPF (Figure 1). No patient was treated with a tyrosine kinase
Table 1 Commonly used criteria for assessing risk of GIST

\begin{tabular}{cl}
\hline NIH criteria ${ }^{14}$ & \\
\hline Very low & $<2 \mathrm{~cm}$ and $<5$ mitotic index \\
Low & $2-5 \mathrm{~cm}$ and $<5$ mitotic index \\
Intermediate & $5-10 \mathrm{~cm}$ and $<5$ mitotic index \\
& $>5 \mathrm{~cm}$ and $6-10$ mitotic index or \\
High & $>5 \mathrm{~cm}$ and $>5$ mittic index or \\
& $>10 \mathrm{~cm}$ and any mitotic index or \\
& Any size and $>10$ mitotic index \\
AFIP criteria ${ }^{16,17}$ & \\
Unknown ${ }^{*}$ & Expect from following criteria \\
Very low & $\leqq 5 \mathrm{~cm}$ and $\leqq 5$ mitotic index \\
Low & Gastric: $>5 \mathrm{~cm}$ and $\leqq 10 \mathrm{~cm}$ and $\leqq 5$ mitotic index \\
Moderate & Others: $>2 \mathrm{~cm}$ and $\leqq 5 \mathrm{~cm}$, and $\leqq 5$ mitotic index \\
& Gastric: $>10 \mathrm{~cm}$ and $\leqq 5$ mitotic index or \\
& $>2 \mathrm{~cm}$ and $\leqq 5 \mathrm{~cm}$, and $>5$ mitotic index \\
High & Others: $>5 \mathrm{~cm}$ and $\leqq 10 \mathrm{~cm}$, and $\leqq 5$ mitotic index \\
& Gastric: $>5 \mathrm{~cm}$ and $>5$ mitotic index \\
& Others: $>10 \mathrm{~cm}$ or $>5$ mitotic index
\end{tabular}

* Category with small numbers of cases insufficient for prediction of malignant potential

$\mathrm{NIH}$ : the National Institutes of Health

AFIP: the Armed Forces Institute of Pathology

Definition for risk categories in the National Institutes of Health and Armed Forces Institute of Pathology criteria.

inhibitor before developing recurrence. As a follow up study, chest and abdominal computed tomography (CT) scans were performed at least every 6 months after surgery on patients with greater than intermediate- or moderate-risk, and at least every year on patients with very low- or low-risk. However, CT scans were repeated earlier whenever clinically indicated depending on the discretion of the investigator. Endoscopy was performed annually. Patients did not undergo any further selection. Follow-up information was obtained during regular outpatient visits or by phone with the patient and/or the referring physician. During follow-up, we analyzed the incidence of disease recurrence. All deaths from other causes were recorded. RFS was defined as the time from patient registration to the development of tumor recurrence.

We estimated RFS probabilities with the Kaplan-Meier method. The relationships of patient and tumor characteristics to outcome were investigated by univariate analysis using the log-rank test. Multivariate analysis could not be performed because of the small number of recurrence events. A p-value of $<0.05$ was considered statistically significant. SPSS statistical software (v.18; Chicago, IL, USA) was used for univariate analysis.

We assessed nomogram performance in 2 ways. First, the discriminatory capability of the nomogram was determined using the concordance index (C index) [16]. The interpretation of the $\mathrm{C}$ index is similar to that of 


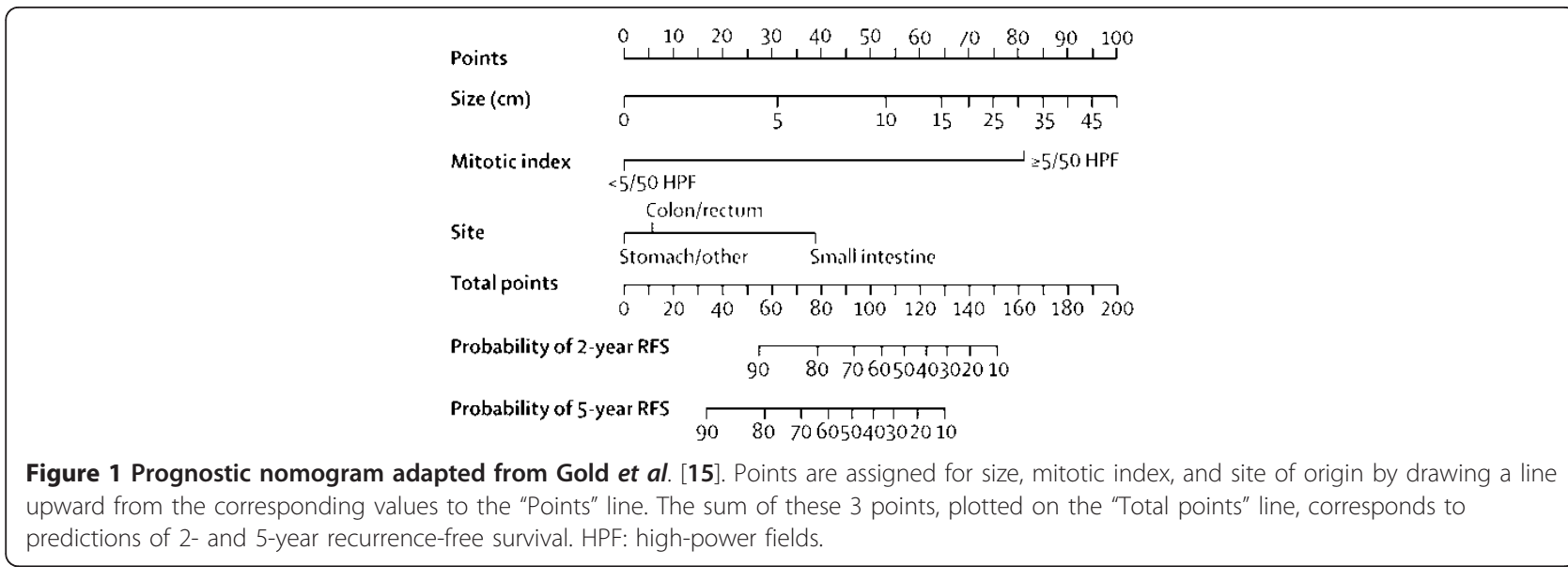

the area under the receiver operating characteristic curve. The $C$ index provides the probability that the nomogram will predict a poorer outcome for the patient who recurred first out of a randomly selected pair of patients. The $C$ index was assessed with respect to 3 groups: all patients, a subgroup excluding very low- and low-risk patients, and a subgroup limited to patients whose tumors were classified as high-risk by either $\mathrm{NIH}$ or AFIP criteria. Second, calibration was evaluated by comparing the Kaplan-Meier-observed RFS for 4 quartiles of patients stratified by nomogram score 2 years after surgical treatment. Calibration was limited to the 2 -year RFS because the median follow-up period was insufficient to estimate the 5-year RFS.

\section{Results}

The detailed clinicopathological features of the patients with primary GISTs are shown in Table 2. The median age of the patients was 63 years (range, 18-83 years), and 31 patients $(51.7 \%)$ were men. Tumor locations included the stomach, small intestine, and rectum in 48 (80\%), 11 (18.3\%), and 1 (1.7\%) patient, respectively. The median tumor size was $3.8 \mathrm{~cm}$ (range, $1.6-20 \mathrm{~cm}$ ). The median duration of follow-up for patients in this series was 4.1 years (range 0.1-12.8 years), with 6 of 60 patients experiencing recurrence. Five of six patients had disease recurrence in the liver, and another had local intrapelvic recurrence. All of these recurrences were detected by follow-up CT scan, with 4 of the recurrence events occurring less than 1 year after surgery. Three patients were lost to follow-up before 2 years. All 3 patients lost to follow-up had very low- or low-risk tumors. According to the NIH criteria, 34 (56.6\%), $13(21.7 \%)$, and $13(21.7 \%)$ tumors were classified as very low- or low-, intermediate-, and high-risk, respectively. According to the AFIP criteria, 3 (5.0\%), 35 (58.3\%), 13 (21.7\%), and $9(15 \%)$ tumors were classified as unknown, very low or low, moderate, and high risk, respectively. In the univariate analysis, size and the mitotic index predicted RFS ( $p=0.002)$. When correlating recurrence with tumor location, a trend toward statistical significance became evident $(\mathrm{p}=0.051)$.

RFS was 93.0\% (SE 0.034\%), and 89.9\% (SE 0.045\%) after 2 and 5 years, respectively (Figure 2). In our series, the 2-year and 5-year RFS was better than that reported previously. RFS-classified risk groups according to the $\mathrm{NIH}$ and AFIP criteria are shown in Figure 3. Recurrence events were observed only in the groups classified as high risk by either set of criteria.

Next, we estimated the discriminatory capability of the nomogram by using the $\mathrm{C}$ index. The $\mathrm{C}$ index of the nomogram prediction for all patients was 0.96 , which was adequately acceptable. The $\mathrm{C}$ indices of the nomogram predictions excluding the low-risk subgroup and limited to only the high-risk subgroup were 0.91 and 0.65 , respectively. Therefore, in $65 \%$ of the cases, the nomogram correctly predicted the order of outcome between 2 randomly selected patients who were classified as high-risk according to either the NIH or AFIP criteria. A calibration test was performed to estimate the accuracy of the RFS predicted by the nomogram. Calibration of the nomogram-predicted RFS tended to overestimate recurrence compared with the Kaplan-Meierobserved RFS (Figure 4).

\section{Discussion}

In our series, 2-year and 5-year RFS was better than that previously reported ( $93.0 \%$ and $89.9 \%$, respectively). There were a large proportion of very low- and low-risk patients. The reasons for the large proportion of lowrisk GISTs may be the excellent screening system and the early indication for surgery. Simply, this may mean that early diagnosis and resection improve the overall survival. Meanwhile, our dataset had an obviously high proportion of smaller tumors than Western datasets. Because of their high mitotic indices, some "small" 
Table 2 Characteristics of 60 patients with primary resectable GISTs

\begin{tabular}{|c|c|c|c|}
\hline Clinicopathological feature & $\mathrm{n}$ (total $=60)$ & Recurrence events $(n=6)$ & univariate analysis $P$ value \\
\hline \multicolumn{4}{|l|}{ Follow up period (years) } \\
\hline median (range) & $2.8(0.1-11.8)$ & & \\
\hline \multicolumn{4}{|l|}{ Sex } \\
\hline Female & 29 & 2 & \\
\hline Male & 31 & 4 & 0.465 \\
\hline \multicolumn{4}{|l|}{ Age (years) } \\
\hline median (range) & $63(18-83)$ & & \\
\hline$\leqq 63$ & 31 & 5 & \\
\hline$>63$ & 29 & 1 & 0.211 \\
\hline \multicolumn{4}{|l|}{ Tumor location(\%) } \\
\hline Stomach & $48(80)$ & 3 & \\
\hline Others & $12(20)$ & 3 & 0.51 \\
\hline \multicolumn{4}{|l|}{ Tumor size $(\mathrm{cm})$} \\
\hline median (range) & $3.8(1.6-20)$ & & \\
\hline$\leqq 5$ & 43 & 1 & \\
\hline$>5$ & 17 & 5 & 0.002 \\
\hline \multicolumn{4}{|l|}{ Mitotic index* } \\
\hline$<5$ & 39 & 0 & \\
\hline$\geqq 5$ & 21 & 6 & 0.002 \\
\hline \multicolumn{4}{|l|}{ Resection margin } \\
\hline Ro & 51 & 4 & \\
\hline R1 & 9 & 2 & 0.156 \\
\hline \multicolumn{4}{|l|}{ NIH criteria (\%) } \\
\hline Very low \& Low & $34(56.6)$ & 0 & \\
\hline Intermediate & $13(21.7)$ & 0 & \\
\hline High & $13(21.7)$ & 6 & \\
\hline \multicolumn{4}{|l|}{ AFIP criteria (\%) } \\
\hline Unknown & $3(5.0)$ & 0 & \\
\hline Very low \& Low & $35(58.3)$ & 0 & \\
\hline Moderate & $13(21.7)$ & 0 & \\
\hline High & $9(15)$ & 6 & \\
\hline
\end{tabular}

*Mitotic index $=$ number of mitoses per 50 high-power fields.

$\mathrm{NIH}$ the National Institutes of Health

AFIP the Armed Forces Institute of Pathology

Detailed clinicopathological features of the patients with primary GISTs and the results of univariate analysis.

GISTs less than $3 \mathrm{~cm}$ in diameter were classified as intermediate- or high-risk tumors. The proportion of "small" GISTs may account for the better prognosis compared to those observed in Western datasets.

Currently, accurate prognostication of GISTs is essential, not only in guiding the clinician regarding the frequency and intensity of postoperative surveillance but also, to enable better selection of tumors for potential adjuvant treatment. In current clinical practice, relatively large numbers of clinicians appear to recommend adjuvant imatinib therapy for patients with high-risk tumors according to the NIH criteria. In the ACOSOG Z9001 trial, one of the few studies of adjuvant imatinib therapy, patients were only stratified according to tumor size, which may not be the only prognostic factor in recent studies, making it difficult to adequately select patients for whom the adjuvant treatment could be clearly beneficial. In 2010, at the Gastrointestinal Cancers Symposium (ASCO-GI), Blackstein et al. reported a stratified analysis of the Z9001 trial using the AFIP criteria. [17] The 2-year RFS of the low-risk patients was $98 \%$ and thus, there was no benefit of adjuvant therapy. The recurrence rate of the high-risk patients selected with 3 factors-tumor size, mitotic index, and tumor locationwas the highest and the high-risk patients gained the greatest effect from imatinib adjuvant therapy. The importance of these 3 factors was also suggested in our present study. Simultaneously, recurrence events were observed only in the group classified as high risk by both the NIH and AFIP criteria and many of these events occurred during the first postoperative period. This result indicates that commonly used criteria 


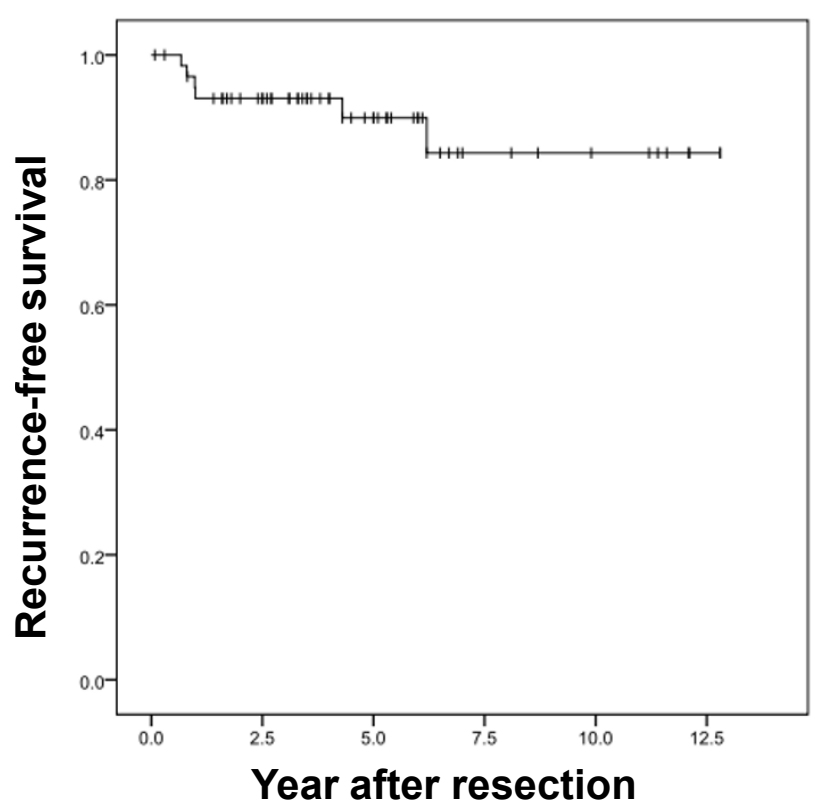

Figure 2 Recurrence-free survival of total patients. Kaplan-Meier estimates of the recurrence-free survival of patients with primary GIST after complete surgical resection.

provide an excellent estimation of tumor behavior. However, regarding adjuvant therapy, the high-risk patients classified by the commonly used criteria do not always include patients who can benefit fully from the use of adjuvant therapy. Huang et al. clearly revealed the limitations of these criteria [4]. The high-risk category has been criticized as being too heterogeneous. According to the results of the SSG XVIII-AIO study, if a long duration of adjuvant therapy is recommended to all high-risk patients, the adverse effects of imatinib adjuvant therapy are not negligible. Considering the cytostatic effect of imatinib, it is speculated that the best

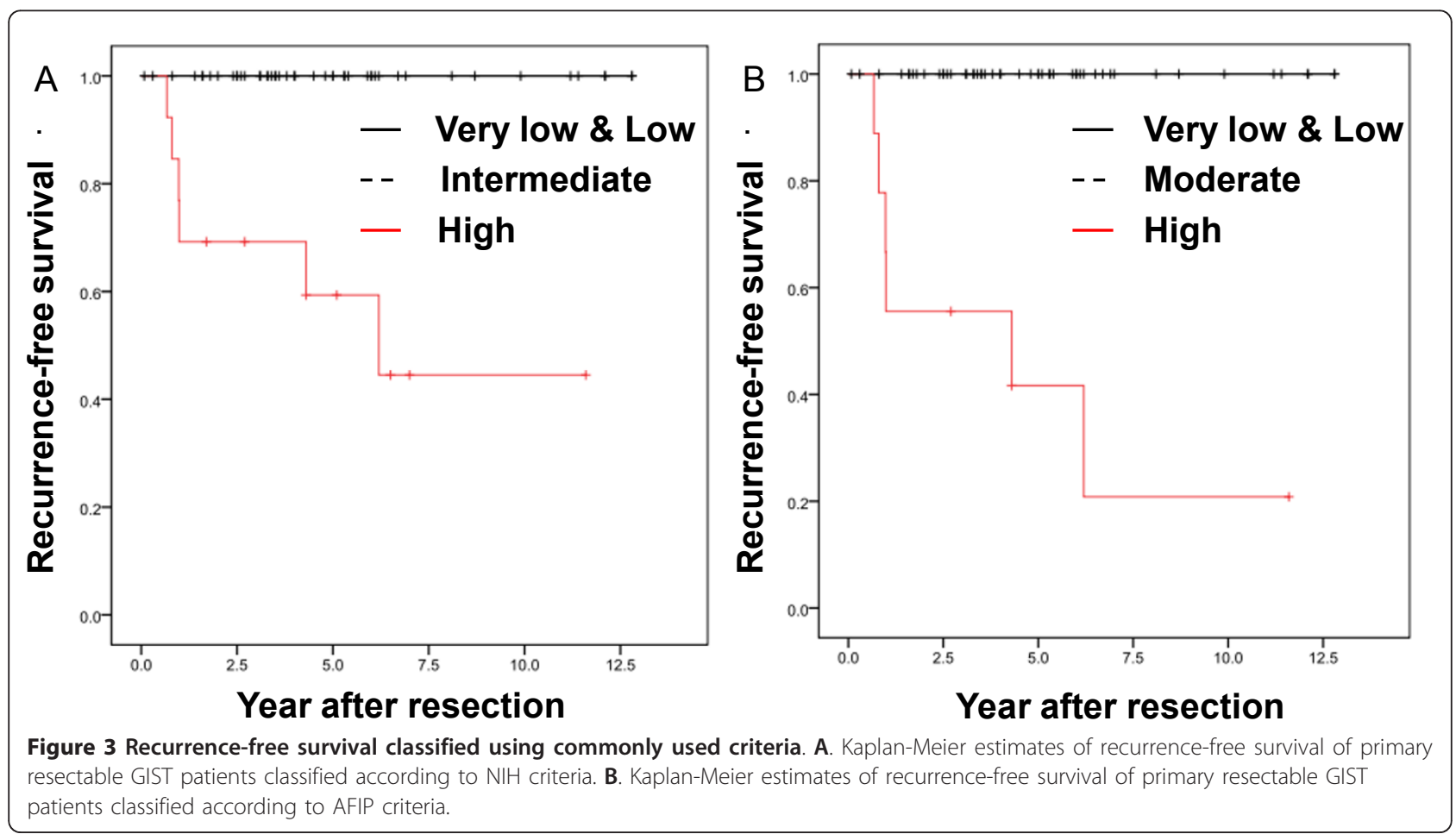




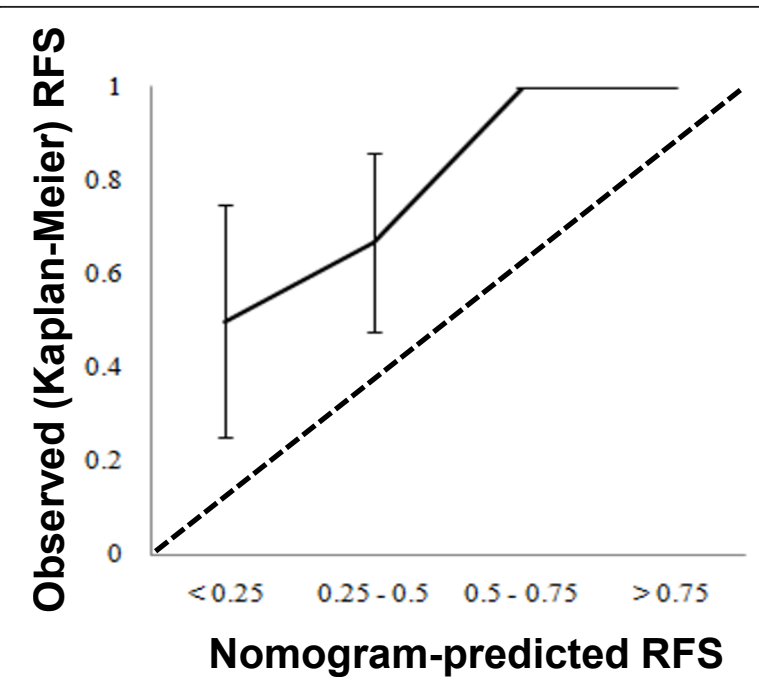

Figure 4 Calibration of nomogram-predicted recurrence-free survival (RFS). Observed RFS is shown compared with nomogrampredicted RFS at 2 years.

indications for long adjuvant therapy are patients who are expected to develop recurrence in the early period after surgery. We experienced 3 "small" GISTs less than $3 \mathrm{~cm}$ in diameter that were classified as high-risk GISTs according to the NIH or AFIP criteria. The patients with these tumors had no recurrences at 1.7, 4.3, and 6.5 years after surgery, respectively. In a practical sense, it is difficult to decide whether adjuvant therapy is necessary for these patients. Naturally, the potential for recurrence and metastasis is lower for smaller tumors. In particular, the Z9001 trial did not reveal the benefit of adjuvant imatinib for small GISTs less than $3 \mathrm{~cm}$, and this minor subset has not been analyzed adequately in Western countries. It is expected that adjuvant therapy for GISTs will be more individualized. Concerning adjuvant therapy, we need more consideration for small GISTs, and small GISTs should be analyzed as a subset with potentially different biological behavior.

Nomograms can estimate tumor size in a continuous but nonlinear fashion and calculate the risk of recurrence at a point in time for any individual patient. No other staging system has been assessed for its ability to assign a quantitative risk of recurrence for individual patients. It might be challenging to justify the use of adjuvant imatinib by nomogram prediction alone because the nomogram prediction overestimated the recurrence risk compared with the actual RFS in our series. However, the discriminatory capability of the nomogram for the subgroup of high-risk patients is worthy of attention $(\mathrm{C}$ index $=0.65)$.

When interpreting the results of the current analysis, it is important to consider the limitation of our dataset.
The small sample size of a single center experience is not sufficient to validate and decide the cut-off value. However, we can suggest the nomogram as a beneficial scoring system in practical situations, but not as a direct RFS predictor.

In addition, the prognostic criteria could be improved with the incorporation of additional variables, for example, mutation status. Gold et al. failed to observe an improvement in the accuracy of the nomogram prediction when mutation status was included [15]. However, conflicting results exist about whether KIT and plateletderived growth factor receptor alpha (PDGFRA) mutation status affect outcome among patients with resected localized primary GISTs [18-26]. Approximately $85 \%$ of GISTs contain an activating mutation in the KIT protooncogene, whereas $3-5 \%$ of patients have a PDGFRA mutation $[12,27,28]$. Moreover, the effect of imatinib varies depending on the domains of KIT and PDGFRA affected by the mutations. Therefore, many uncertainties remain regarding techniques to assess prognostic factors, including whether tumor size should be measured before or after fixation and whether the most mitotically active tumor areas should be assessed, as well as regarding the dosage and duration of imatinib adjuvant therapy. Given these uncertainties, longer follow-ups and results from additional trials are needed.

\section{Conclusions}

Although the commonly used criteria provide an excellent estimation of tumor behavior, they are limited by the prognostic heterogeneity of their high-risk tumor categories. The predictive nomogram is a beneficial scoring system but not a direct RFS predictor. We need more consideration for small GISTs, particularly those less than $3 \mathrm{~cm}$ in diameter, and small GISTs should be analyzed as a subset with potentially different biological behavior.

\section{List of abbreviations}

GIST: gastrointestinal stromal tumors; RFS: recurrence-free survival; ACOSOG: American College of Surgeons Oncology Group; NIH: National Institutes of Health; HPFs: high-power fields; AFIP: Armed Forces Institute of Pathology; C index: concordance index; PDGFRA: platelet-derived growth factor receptor alpha.

\section{Authors' contributions}

NT collected data, performed analysis, and drafted, revised and finalized the manuscript. KT conceived this study and participated in its design and coordination. TS, NT, and $\mathrm{HO}$ revised and approved the contents of the manuscript. All authors read and approved the final manuscript.

\section{Authors' information}

Department of Surgery, Division of Frontier Medical Science, Graduate School of Biomedical Sciences, Hiroshima University

Competing interests

The authors declare that they have no competing interests. 
Received: 27 October 2011 Accepted: 20 February 2012

Published: 20 February 2012

\section{References}

1. Blay JY, Bonvalot S, Casali P, Choi H, Debiec-Richter M, Dei Tos AP, Emile JF, Gronchi A, Hogendoorn PC, Joensuu $\mathrm{H}$, et al: Consensus meeting for the management of gastrointestinal stromal tumors. Report of the GIST Consensus Conference of 20-21 March 2004, under the auspices of ESMO. Ann Oncol 2005, 16:566-578.

2. Demetri GD, von Mehren M, Antonescu CR, DeMatteo RP, Ganjoo KN, Maki RG, Pisters PW, Raut CP, Riedel RF, Schuetze S, et al: NCCN Task Force report: update on the management of patients with gastrointestinal stromal tumors. J Natl Compr Canc Netw 8(Suppl 2):S1-41, quiz S42-44.

3. DeMatteo RP, Lewis JJ, Leung D, Mudan SS, Woodruff JM, Brennan MF: Two hundred gastrointestinal stromal tumors: recurrence patterns and prognostic factors for survival. Ann Surg 2000, 231:51-58.

4. Huang HY, Li CF, Huang WW, Hu TH, Lin CN, Uen YH, Hsiung CY, Lu D: A modification of $\mathrm{NIH}$ consensus criteria to better distinguish the highly lethal subset of primary localized gastrointestinal stromal tumors: a subdivision of the original high-risk group on the basis of outcome. Surgery 2007, 141:748-756.

5. Rutkowski P, Nowecki Zl, Michej W, Debiec-Rychter M, Wozniak A, Limon J, Siedlecki J, Grzesiakowska U, Kakol M, Osuch C, et al: Risk criteria and prognostic factors for predicting recurrences after resection of primary gastrointestinal stromal tumor. Ann Surg Oncol 2007, 14:2018-2027.

6. Joensuu H, Roberts PJ, Sarlomo-Rikala M, Andersson LC, Tervahartiala P, Tuveson D, Silberman S, Capdeville R, Dimitrijevic S, Druker B, Demetri GD: Effect of the tyrosine kinase inhibitor STI571 in a patient with a metastatic gastrointestinal stromal tumor. N Engl J Med 2001, 344:1052-1056.

7. Blanke $C D$, Demetri $G D$, von Mehren $M$, Heinrich $M C$, Eisenberg $B$ Fletcher JA, Corless CL, Fletcher CD, Roberts PJ, Heinz D, et al: Long-term results from a randomized phase II trial of standard- versus higher-dose imatinib mesylate for patients with unresectable or metastatic gastrointestinal stromal tumors expressing KIT. J Clin Oncol 2008, 26:620-625.

8. Demetri GD, von Mehren $M$, Blanke CD, Van den Abbeele AD, Eisenberg $B$, Roberts PJ, Heinrich MC, Tuveson DA, Singer S, Janicek M, et al: Efficacy and safety of imatinib mesylate in advanced gastrointestinal stromal tumors. N Engl J Med 2002, 347:472-480.

9. Blanke CD, Rankin C, Demetri GD, Ryan CW, von Mehren M, Benjamin RS, Raymond AK, Bramwell VH, Baker LH, Maki RG, et al: Phase III randomized, intergroup trial assessing imatinib mesylate at two dose levels in patients with unresectable or metastatic gastrointestinal stromal tumors expressing the kit receptor tyrosine kinase: S0033. J Clin Oncol 2008, 26:626-632.

10. Verweij J, Casali PG, Zalcberg J, LeCesne A, Reichardt P, Blay JY, Issels R, van Oosterom A, Hogendoorn PC, Van Glabbeke M, et al: Progression-free survival in gastrointestinal stromal tumours with high-dose imatinib: randomised trial. Lancet 2004, 364:1127-1134.

11. Dematteo RP, Ballman KV, Antonescu CR, Maki RG, Pisters PW, Demetri GD, Blackstein ME, Blanke CD, von Mehren M, Brennan MF, et al: Adjuvant imatinib mesylate after resection of localised, primary gastrointestina stromal tumour: a randomised, double-blind, placebo-controlled trial. Lancet 2009, 373:1097-1104.

12. Fletcher CD, Berman JJ, Corless C, Gorstein F, Lasota J, Longley BJ, Miettinen M, O'Leary $T$, Remotti $H$, Rubin BP, et al: Diagnosis of gastrointestinal stromal tumors: A consensus approach. Hum Pathol 2002, 33:459-465.

13. Miettinen M, El-Rifai W, L HLS, Lasota J: Evaluation of malignancy and prognosis of gastrointestinal stromal tumors: a review. Hum Pathol 2002, 33:478-483.

14. Miettinen M, Lasota J: Gastrointestinal stromal tumors: review on morphology, molecular pathology, prognosis, and differential diagnosis. Arch Pathol Lab Med 2006, 130:1466-1478.

15. Gold JS, Gonen M, Gutierrez A, Broto JM, Garcia-del-Muro X, Smyrk TC, Maki RG, Singer S, Brennan MF, Antonescu CR, et al: Development and validation of a prognostic nomogram for recurrence-free survival after complete surgical resection of localised primary gastrointestinal stromal tumour: a retrospective analysis. Lancet Oncol 2009, 10:1045-1052.
16. Harrell FE Jr, Califf RM, Pryor DB, Lee KL, Rosati RA: Evaluating the yield of medical tests. JAMA 1982, 247:2543-2546.

17. Blackstein ME, Corless CL, Ballman KV, Antonescu C, Blanke C, Demetri GD, Mehren MV, Maki RG, Pisters PW, DeMatteo RP: Risk assessment for tumor recurrence after surgical resection of localized primary gastrointestinal stromal tumor (GIST): North American Intergroup phase III trial ACOSOG Z9001. Orlando; 2010.

18. Taniguchi M, Nishida T, Hirota S, Isozaki K, Ito T, Nomura T, Matsuda H, Kitamura Y: Effect of c-kit mutation on prognosis of gastrointestinal stromal tumors. Cancer Res 1999, 59:4297-4300.

19. Singer $S$, Rubin $B P$, Lux ML, Chen $C J$, Demetri GD, Fletcher CD, Fletcher JA: Prognostic value of KIT mutation type, mitotic activity, and histologic subtype in gastrointestinal stromal tumors. J Clin Oncol 2002, 20:3898-3905

20. Kim TW, Lee H, Kang YK, Choe MS, Ryu MH, Chang HM, Kim JS, Yook JH, Kim BS, Lee JS: Prognostic significance of c-kit mutation in localized gastrointestinal stromal tumors. Clin Cancer Res 2004, 10:3076-3081.

21. Liu XH, Bai CG, Xie Q, Feng F, Xu ZY, Ma DL: Prognostic value of KIT mutation in gastrointestinal stromal tumors. World J Gastroenterol 2005, 11:3948-3952.

22. Andersson J, Bumming P, Meis-Kindblom JM, Sihto H, Nupponen N, Joensuu H, Oden A, Gustavsson B, Kindblom LG, Nilsson B: Gastrointestinal stromal tumors with KIT exon 11 deletions are associated with poor prognosis. Gastroenterology 2006, 130:1573-1581.

23. Cho S, Kitadai Y, Yoshida S, Tanaka S, Yoshihara M, Yoshida K, Chayama K Deletion of the KIT gene is associated with liver metastasis and poor prognosis in patients with gastrointestinal stromal tumor in the stomach. Int J Oncol 2006, 28:1361-1367.

24. Keun Park C, Lee EJ, Kim M, Lim HY, Choi DI, Noh JH, Sohn TS, Kim S, Kim MJ, Lee HK, Kim KM: Prognostic stratification of high-risk gastrointestinal stromal tumors in the era of targeted therapy. Ann Surg 2008, 247:1011-1018

25. Tzen CY, Wang MN, Mau BL: Spectrum and prognostication of KIT and PDGFRA mutation in gastrointestinal stromal tumors. Eur J Surg Oncol 2008, 34:563-568.

26. Yamaguchi U, Nakayama R, Honda K, Ichikawa H, Hasegawa T, Shitashige M, Ono M, Shoji A, Sakuma T, Kuwabara $H$, et al: Distinct gene expressiondefined classes of gastrointestinal stromal tumor. J Clin Oncol 2008, 26:4100-4108.

27. Heinrich $M C$, Corless $C L$, Demetri $G D$, Blanke $C D$, von Mehren $M$, Joensuu H, McGreevey LS, Chen CJ, Van den Abbeele AD, Druker BJ, et al: Kinase mutations and imatinib response in patients with metastatic gastrointestinal stromal tumor. J Clin Oncol 2003, 21:4342-4349.

28. Miettinen M, Majidi M, Lasota J: Pathology and diagnostic criteria of gastrointestinal stromal tumors (GISTs): a review. Eur J Cancer 2002, 38(Suppl 5):S39-51.

doi:10.1186/1477-7819-10-43

Cite this article as: Tanimine et al.: Prognostic criteria in patients with gastrointestinal stromal tumors: a single center experience retrospective analysis. World Journal of Surgical Oncology 2012 10:43.

\section{Submit your next manuscript to BioMed Central and take full advantage of:}

- Convenient online submission

- Thorough peer review

- No space constraints or color figure charges

- Immediate publication on acceptance

- Inclusion in PubMed, CAS, Scopus and Google Scholar

- Research which is freely available for redistribution

Submit your manuscript at www.biomedcentral.com/submit
C Biomed Central 